\title{
Antenna phase center correction differences from robot and chamber calibrations: the case study LEIAR25
}

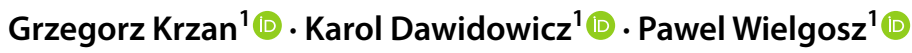

Received: 23 April 2019 / Accepted: 27 January 2020 / Published online: 11 February 2020

(c) The Author(s) 2020

\begin{abstract}
In recent years, the Global Navigation Satellite Systems (GNSS) have been intensively modernized, resulting in the introduction of new carrier frequencies for GPS and GLONASS and the development of new satellite systems such as Galileo and BeiDou (BDS). For this reason, the absolute field antenna calibrations performed so far for the two legacy carrier frequencies, the GPS and GLONASS, seem to be insufficient. Hence, all antennas will require a re-calibration of their phase center variations for the new signals to ensure the highest measurement accuracy. Currently, two absolute calibration methods are used to calibrate GNSS antennas: field calibration using a robot and calibration in an anechoic chamber. Unfortunately, differences in these methodologies also result in a disparity in the obtained antenna phase center corrections (PCC). Therefore, we analyze the differences between individual PCC obtained with these two methods, specifically for the Leica AR-25 antenna model (LEIAR25). In addition, the influence of PCC differences on the GNSS-derived position time series for 19 EUREF Permanent GNSS Network (EPN) stations was also assessed. The results show that the calibration method has a noticeable impact on PCC models. PCC differences determined for the ionosphere-free combination may reach up over $20 \mathrm{~mm}$ and can be transferred to the position domain. Further tests concerning the positioning accuracy showed that for horizontal coordinates differences between solutions were mostly below $1 \mathrm{~mm}$, exceeding $2 \mathrm{~mm}$ only at two stations for the GLONASS solution. However, the height component differences exceeded $5 \mathrm{~mm}$ for four, six and six stations out of 19 for the GPS, GLONASS and Galileo solutions, respectively. These differences are strongly dependent on large L2 calibration differences.
\end{abstract}

Keywords GNSS · Chamber calibration · Robot calibration · PCC · PPP · Position time series

\section{Introduction}

In recent years, the Global Navigation Satellite Systems (GNSS) have been intensively modernized, the result of which is, among others, the introduction of new carrier frequencies to GPS and GLONASS and the development of new satellite systems like Galileo and BeiDou (BDS). The increase in the number of GNSS satellites and the introduction of new signals will allow for faster and more accurate position determination and increase the availability of precise solutions, especially in difficult measurement conditions. The growing number of satellites and signals will enable more accurate modeling of error sources such as orbits and clock biases and atmospheric corrections.

Grzegorz Krzan

grzegorz.krzan@uwm.edu.pl

1 University of Warmia and Mazury in Olsztyn, ul. Oczapowskiego 2, 10-719 Olsztyn, Poland
One of the crucial sources of biases in GNSS measurements, which is very important for precise positioning, is the phase error introduced by both transmitter and receiver antenna, as was demonstrated by Rothacher et al. (1995). This error is related to the antenna phase center (APC), which IEEE Standard Definitions of Terms for Antennas (2014) defines as "the location of a point associated with an antenna such that, if it is taken as the center of a sphere whose radius extends into the far field, the phase of a given field component over the surface of the radiation sphere is essentially constant, at least over that portion of the surface where the radiation is significant." This point varies depending on the direction and frequency of the incoming signal. For practical purposes, we define some interim points. The mean phase center (MPC) is defined as the point at which the signal phase has the smallest phase center variations (PCV). The height of the antenna above the physical surveying point is usually referred to the antenna reference point (ARP). The International GNSS Service (IGS) defines the ARP as the 
intersection of the vertical symmetry axis of the antenna with its bottom plane. The antenna phase center offset (PCO) is a vector connecting the ARP and MPC. The difference between the instant position of the antenna phase center and the MPC is referred to as the PCV (Fig. 1). Additionally, $r$ is the radius of a perfect phase sphere originating at MPC.

The instant phase center correction (PCC) is a function of PCO and PCV (Wübbena et al. 1997):

$\operatorname{PCC}(\alpha, z)=r+\mathrm{PCO} \cdot \vec{e}+\operatorname{PCV}(\alpha, z)$,

where $\alpha$ and $z$ are the horizontal and zenithal angles in the antenna body frame and $\vec{e}$ the line-of-sight unit vector.

The most commonly used methods for providing receiver antenna PCC are (1) absolute field or (2) chamber calibrations. The field calibration is based on GNSS measurements carried out at two closely placed points. The first variant of the method was proposed by Wübbena et al. (1997). In this approach, based on the creation of sidereal time differences of observations, the calibration of one antenna requires at least 2 days of measurements. Mader (1999) later developed a relative calibration system, again on two nearby points, and these results were adopted by IGS for its early network processing. The technique has been further improved by shortening the calibration time, which was possible when using a robot that rotates the calibrated antenna between two consecutive measurements (Wübbena et al. 2000; Bilich and Mader 2010). By moving the antenna being calibrated on a robot, its phase behavior can be separated from a reference antenna, thereby creating an "absolute calibration" independent of the phase characteristics of the reference antenna. The advantage of the method is that it is based on real GNSS signals recorded in the natural environment considering signal strength and all affecting effects, e.g., ionospheric and tropospheric delays. The relatively long time (about 2-24 h) needed to determine the final model for one antenna can be regarded as a disadvantage.

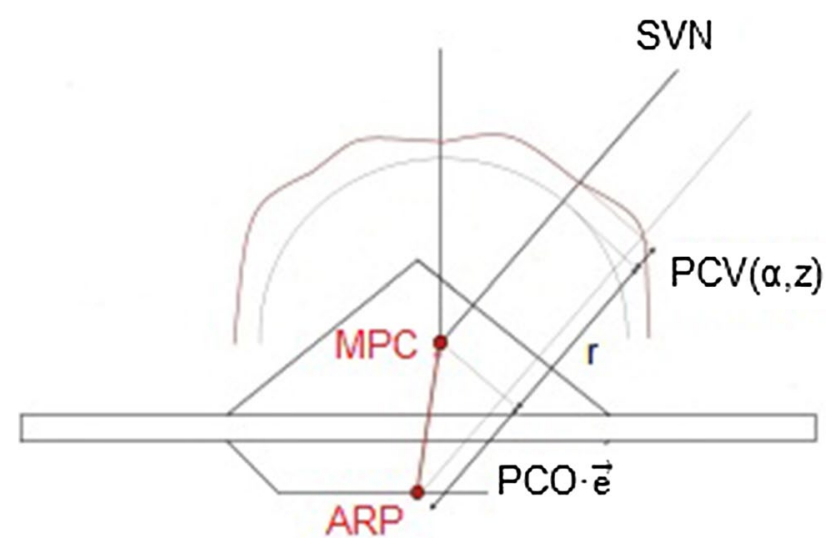

Fig. 1 Main receiver antenna points and their spatial relations
Calibration in an anechoic chamber is the second popular method of developing PCC patterns. The main advantage of the chamber method is a short calibration time and the same conditions for all antennas. However, the test signal is simulated and is not subject to all disturbing phenomena as the real GNSS signals, since it does not originate from a satellite. Some authors consider this as a disadvantage of the chamber method (Görres et al. 2006; Aerts and Moore 2013). Since there is still ongoing discussion on which of these methods is better, when available, PCC determined by both calibration methods are often provided by GNSS network operators using Antenna Exchange Format (ANTEX) files.

With the addition of new GNSS constellations with their new signals, the results of the current GNSS antenna absolute calibrations usually available for only two legacy carrier frequencies of GPS and GLONASS seem to be insufficient. Therefore, all antennas dedicated to precise geodetic, geophysical and surveying applications may require re-calibration to ensure the highest measurement accuracy.

In the last years, few authors conducted research concerning differences in the antenna calibration models determined by robot and chamber techniques (Stępniak et al. 2015). Aerts and Moore (2013) studied the differences observed between the antenna type means obtained from the University of Bonn's anechoic chamber and the robot-derived type means in the igs08.atx file. Noting the relationship between antenna models and differences between calibration results, they formulated recommendations for all relevant antennas. Araszkiewicz and Völksen (2017) compared type mean and individual antenna calibration models and demonstrated that for some antennas, the discrepancy in the position resulting from the utilized calibration model can reach $10 \mathrm{~mm}$ in both horizontal and vertical components. However, for most antennas, these offsets did not exceed 2-mm horizontal and 4-mm vertical components, respectively. An interesting issue is also the impact of multipath and its mitigation using appropriate antenna calibration. Dilssner et al. (2008) conducted research on the impact of near-field effects on GNSS position solutions. They showed that mechanical structures mounted underneath the antennas could cause significant changes in the PCC resulting in systematic height errors of $1-2 \mathrm{~cm}$ for midlatitude locations to even $4-5 \mathrm{~cm}$ in polar regions. Aerts (2011) showed that differences between the chamber and robot calibration results had a systematic character. The cause is not clear, but the author suggests that reasons might be measurement noise, different measurement techniques used and multipath effects.

In our study, we compare individual PCC models derived from robot calibration at $\mathrm{GEO}++$ and chamber calibration at the University of Bonn for the single antenna model. The effects of the PCC differences on the station coordinate time series for 19 EPN stations are also examined. All test 
stations were equipped with LEIAR25 antennas in different configurations. The focus, however, is analyzing the consistency of both calibration methods.

\section{Methodology}

At the first stage, the results from the anechoic chamber and the absolute field calibration method were compared for selected examples of antennas to analyze the differences in PCC models. The main PCC components include:

- North, East, Up PCO for different frequencies and systems,

- PCV as a function of elevation for different frequencies and systems,

- PCV as a function of elevation and azimuth for different frequencies and systems (Rothacher and Schmid 2010).

The exact knowledge of PCO and PCV values is necessary to determine PCC. The PCC comparison was based on the approach presented by Kersten and Schön (2016). At the first stage, in order to achieve a common datum, the results of chamber-derived PCV were shifted to $\operatorname{PCV}(\alpha, 0)=0$, as it is adopted in robot calibrations. This was done by adding to all chamber-derived PCV a constant shift $\delta$ equal to:

$\delta=-\operatorname{PCV}(a, 0)$.

The next step was reducing the PCC values obtained during calibration in the anechoic chamber to the PCO obtained from absolute field calibration, which can be done using the general formula (Kersten and Schön 2016):

$\mathrm{PCC}(\alpha, z)=s^{\mathrm{T}} \mathrm{PCO}_{\mathrm{r}}+\left(\mathrm{PCV}_{\mathrm{c}}(\alpha, z)+s^{\mathrm{T}}\left(\mathrm{PCO}_{\mathrm{c}}-\mathrm{PCO}_{\mathrm{r}}\right)\right)+r$,

where PCC is the reduced chamber-derived PCC to PCO obtained as a result of absolute field calibration, $\mathrm{PCO}_{\mathrm{r}}$ is the robot-derived PCO, $\mathrm{PCV}_{\mathrm{c}}$ is the chamber-derived PCV and $\mathrm{PCO}_{\mathrm{c}}$ is the chamber-derived $\mathrm{PCO}$.

The robot and chamber-derived PCV were compared by forming difference patterns (dPCC). Then, dPCC for L1 and L2 as well as for ionosphere-free combination (IF) were calculated for GPS, GLONASS and Galileo signals. It should be noted that the ANTEX files with field robot calibrations contain PCC only for L1 and L2 frequencies of GPS and GLONASS systems. They do not have corrections for Galileo, which, however, are adopted from the GPS L1 and L2 corrections (Montenbruck et al. 2017). The calibrations in the anechoic chamber, on the other hand, have a full set of corrections for all GPS, GLONASS and Galileo signals.

The ionosphere-free (IF) combination is commonly used in static processing. As a result of forming the IF combination, the first order of ionospheric path delay is virtually eliminated. The general formula of the IF combinations for code and phase observations is as follows:

$P_{\mathrm{IF}}^{r, s}=\alpha_{i j} P_{i}^{r, s}+\beta_{i j} P_{j}^{r, s}$

$L_{\mathrm{IF}}^{r, s}=\alpha_{i j} L_{i}^{r, s}+\beta_{i j} L_{j}^{r, s}$,

where $P_{\mathrm{IF}}^{r, s}$ and $L_{\mathrm{IF}}^{r, s}$ are the IF combination for code and phase observations between satellite $s$ and receiver $r$, and $\alpha_{i j}$ and $\beta_{i j}$ are the coefficients of the IF combination. $P_{i}^{r, s}, P_{j}^{r, s}, L_{i}^{r, s}$, $L_{j}^{r, s}$ are pseudorange and phase observations in meters for $f_{i}$ and $f_{j}$ frequencies, respectively. The coefficients $\alpha_{i j}$ and $\beta_{i j}$ equal to 2.55 and -1.55 for the L1 and L2, respectively, and can be expressed as

$\alpha_{i j}=\frac{f_{1}^{2}}{f_{1}^{2}-f_{2}^{2}}, \quad \beta_{i j}=\frac{-f_{2}^{2}}{f_{1}^{2}-f_{2}^{2}}$,

where $f_{1}$ and $f_{2}$ indicate the frequencies of the L1 and L2 signals, respectively. However, in addition to removing the effects of the ionosphere from observations, the IF combination increases the observation noise threefold.

In this study, GNSS data from 19 EPN stations (Table 1) covering the whole year of 2017 were used for the analyses in the positioning domain. Individual antenna calibrations in the anechoic chamber were performed by the Institute of Geodesy and Geoinformation (IGG), University of Bonn. Individual calibrations using the absolute field method were carried out by Geo++ company (Garbsen, Germany). The individual PCC models are available at the EPN Web site.

The precise point positioning (PPP) technique, applying the IF combination, was utilized in the study to obtain the precise position of the stations analyzed. For all calculations, we used the NAvigation Package for Earth Observation Satellites (NAPEOS) software (Springer 2009). A PPP approach based on general weighted least squares parameter estimation was used in post-processing mode. Detailed parameters of the processing are presented in Table 2.

PPP solution was performed in four variants: using GPS, GLONASS and Galileo observations separately and then in combination of GPS + GLONASS + Galileo. For each solution, all processing options were identical. These four solutions were calculated for both types of antenna calibration models (field and chamber). Since all processing parameters can be considered identical in each calibration-type solution pair, the differences in coordinates can be treated as the consequence of the differences revealed in the antenna calibration models. The estimated coordinates obtained in IGS14 reference frame were transformed into European Terrestrial Reference Frame 2014 (ETRF2014) using formulas from EUREF Technical Note 
Table 1 Hardware characteristics of the test stations from EPN

\begin{tabular}{|c|c|c|c|}
\hline \multirow[t]{2}{*}{ Station } & \multicolumn{2}{|l|}{ Station hardware } & \multirow{2}{*}{$\begin{array}{l}\text { Individual PCC models available at: http://www.epncb.oma.be/ftp/station/ } \\
\text { general/indiv_calibrations/ (Accessed } 10 \text { April 2019) } \\
\text { PCC ANTEX file names }\end{array}$} \\
\hline & Antenna type & Receiver type & \\
\hline AUBG & LEIAR25.R4 LEIT & Leica GR25 & $\begin{array}{l}\text { LEIAR25.R4-LEIT-11013-GEO-20100901-AUBG.atx } \\
\text { LEIAR25.R4-LEIT-11013-BONN-20101028-AUBG.atx }\end{array}$ \\
\hline BORJ & LEIAR25.R3 LEIT & Javad TRE_3 DELTA & $\begin{array}{l}\text { LEIAR25.R3-LEIT-00021-GEO-20100628-BORJ.atx } \\
\text { LEIAR25.R3-LEIT-00021-BONN-20100806-BORJ.atx }\end{array}$ \\
\hline DIEP & LEIAR25.R4 LEIT & Leica GR25 & $\begin{array}{l}\text { LEIAR25.R4-LEIT-25268-GEO-20120928-DIEP.atx } \\
\text { LEIAR25.R4-LEIT-25268-BONN-20130220-DIEP.atx }\end{array}$ \\
\hline DILL & LEIAR25.R4 LEIT & Leica GR25 & $\begin{array}{l}\text { LEIAR25.R4-LEIT-25058-GEO-20110708-DILL.atx } \\
\text { LEIAR25.R4-LEIT-25058-BONN-20110912-DILL.atx }\end{array}$ \\
\hline DOUR & LEIAR25.R3 NONE & Septentrio PolaRX4 & $\begin{array}{l}\text { LEIAR25.R3-NONE-00021-GEO-20100326-DOUR.atx } \\
\text { LEIAR25.R3-NONE-00021-BONN-20100823-DOUR.atx }\end{array}$ \\
\hline EUSK & LEIAR25.R4 LEIT & Leica GR25 & $\begin{array}{l}\text { LEIAR25.R4-LEIT-25299-GEO-20111110-EUSK.atx } \\
\text { LEIAR25.R4-LEIT-25299-BONN-20120302-EUSK.atx }\end{array}$ \\
\hline GELL & LEIAR25.R4 LEIT & Leica GR25 & $\begin{array}{l}\text { LEIAR25.R4-LEIT-25266-GEO-20120924-GELL.atx } \\
\text { LEIAR25.R4-LEIT-25266-BONN-20130220-GELL.atx }\end{array}$ \\
\hline GOR2 & LEIAR25.R4 LEIT & Leica GR25 & $\begin{array}{l}\text { LEIAR25.R4-LEIT-25057-GEO-20110729-GOR2.atx } \\
\text { LEIAR25.R4-LEIT-25057-BONN-20110912-GOR2.atx }\end{array}$ \\
\hline HEL2 & LEIAR25.R3 LEIT & Leica GR25 & $\begin{array}{l}\text { LEIAR25.R3-LEIT-20025-GEO-20100429-HEL2.atx } \\
\text { LEIAR25.R3-LEIT-20025-BONN-20100525-HEL2.atx }\end{array}$ \\
\hline HELG & LEIAR25.R4 LEIT & Javad TRE_G3TH DELTA & $\begin{array}{l}\text { LEIAR25.R4-LEIT-25559-GEO-20130110-HELG.atx } \\
\text { LEIAR25.R4-LEIT-25559-BONN-20130312-HELG.atx }\end{array}$ \\
\hline HOFJ & LEIAR25.R4 LEIT & Leica GR25 & $\begin{array}{l}\text { LEIAR25.R4-LEIT-11018-GEO-20100903-HOFJ.atx } \\
\text { LEIAR25.R4-LEIT-11018-BONN-20101028-HOFJ.atx }\end{array}$ \\
\hline ISTA & LEIAR25.R4 LEIT & Leica GR25 & $\begin{array}{l}\text { LEIAR25.R4-LEIT-26339-GEO-20150813-ISTA.atx } \\
\text { LEIAR25.R4-LEIT-26339-BONN-20151013-ISTA.atx }\end{array}$ \\
\hline KARL & LEIAR25.R4 LEIT & Javad TRE_3 DELTA & $\begin{array}{l}\text { LEIAR25.R4-LEIT-25092-GEO-20110707-KARL.atx } \\
\text { LEIAR25.R4-LEIT-25092-BONN-20110912-KARL.atx }\end{array}$ \\
\hline LDB2 & LEIAR25.R4 LEIT & Leica GR25 & $\begin{array}{l}\text { LEIAR25.R4-LEIT-25072-GEO-20110725-LDB2.atx } \\
\text { LEIAR25.R4-LEIT-25072-BONN-20110913-LDB2.atx }\end{array}$ \\
\hline LEIJ & LEIAR25.R3 LEIT & Javad TRE_G3TH DELTA & $\begin{array}{l}\text { LEIAR25.R3-LEIT-90011-GEO-20100427-LEIJ.atx } \\
\text { LEIAR25.R3-LEIT-90011-BONN-20100525-LEIJ.atx }\end{array}$ \\
\hline RANT & LEIAR25.R4 LEIT & Javad TRE_G3TH DELTA & $\begin{array}{l}\text { LEIAR25.R4-LEIT-25552-GEO-20130111-RANT.atx } \\
\text { LEIAR25.R4-LEIT-25552-BONN-20130311-RANT.atx }\end{array}$ \\
\hline SAS2 & LEIAR25.R4 LEIT & Javad TRE_G3TH DELTA & $\begin{array}{l}\text { LEIAR25.R4-LEIT-25558-GEO-20130111-SAS2.atx } \\
\text { LEIAR25.R4-LEIT-25558-BONN-20130312-SAS2.atx }\end{array}$ \\
\hline WARN & LEIAR25.R3 LEIT & Javad TRE_G3TH DELTA & $\begin{array}{l}\text { LEIAR25.R3-LEIT-50002-GEO-20100701-WARN.atx } \\
\text { LEIAR25.R3-LEIT-50002-BONN-20100806-WARN.atx }\end{array}$ \\
\hline WRLG & LEIAR25.R3 LEIT & Leica GR25 & $\begin{array}{l}\text { LEIAR25.R3-LEIT-40009-GEO-20100816-WRLG.atx } \\
\text { LEIAR25.R3-LEIT-40009-BONN-20101203-WRLG.atx }\end{array}$ \\
\hline
\end{tabular}

Table 2 Detailed parameters of the test PPP solution

\begin{tabular}{|c|c|}
\hline Basic observables & Undifferenced carrier phases and pseudoranges \\
\hline Orbit and clock products & ESA precise final orbit and clock (30 s) products \\
\hline Ionospheric delay & First-order effect: accounted for dual-frequency ionosphere-free linear combination; second-order effect: no corrections applied \\
\hline Tropospheric delay & $\begin{array}{l}\text { Zenith dry delay computed using the Saastamoinen model with pressure and temperature from the GPT model; the resulting zenith delay is mapped } \\
\text { using the dry GMF mapping function (Boehm et al. 2007); wet delay estimated using the wet GMF mapping function }\end{array}$ \\
\hline Ocean loadings & Computed for FES2004 model using ONSALA ocean loading service (Lyard et al. 2006) \\
\hline Tidal displacement & In accordance with IERS2010 (Petit and Luzum 2010) \\
\hline Satellite clock correction & Second-order relativistic correction for nonzero orbit ellipticity $(-2 \times R \times V / c)$ applied \\
\hline Observation weighting & Carrier phase: $10 \mathrm{~mm}$ sigma (for zenith); pseudorange: $1 \mathrm{~m}$ sigma (for zenith); sigmas increase with increasing zenith angle using the function $(1 / \cos (z))$ \\
\hline Other & Observation sampling rate: $5 \mathrm{~min}$; elevation angle cutoff $5^{\circ} ; 365$ daily sessions \\
\hline
\end{tabular}


Table 3 Reference coordinates in ETRF2014

Fig. 2 Azimuth and elevationdependent PCC differences (dPCC) obtained by comparison of chamber and robot calibration results for the LEIAR25. R3 NONE antenna at station DOUR. The units are $\mathrm{mm}$

\begin{tabular}{|c|c|c|c|c|c|}
\hline \multirow[t]{2}{*}{ No. } & \multirow[t]{2}{*}{ Station } & \multirow[t]{2}{*}{ Epoch } & \multicolumn{3}{|c|}{ Station coordinates $(\mathrm{m})$} \\
\hline & & & $X$ & $Y$ & $Z$ \\
\hline 1 & AUBG & 2017.5 & $4,164,313.422$ & $803,525.331$ & $4,748,474.618$ \\
\hline 2 & BORJ & 2017.5 & $3,769,403.225$ & $440,563.971$ & $5,109,098.920$ \\
\hline 3 & DIEP & 2017.5 & $3,842,153.318$ & $563,401.606$ & $5,042,888.272$ \\
\hline 4 & DILL & 2017.5 & $4,132,892.637$ & $485,478.928$ & $4,817,740.276$ \\
\hline 5 & DOUR & 2017.5 & $4,086,778.365$ & $328,451.704$ & $4,869,782.464$ \\
\hline 6 & EUSK & 2017.5 & $4,022,106.456$ & $477,010.811$ & $4,910,840.575$ \\
\hline 7 & GELL & 2017.5 & $3,688,287.733$ & $941,627.598$ & $5,100,607.900$ \\
\hline 8 & GOR2 & 2017.5 & $3,767,160.372$ & $756,144.691$ & $5,073,919.822$ \\
\hline 9 & HEL2* & 2016.9 & $3,705,183.249$ & $512,589.480$ & $5,148,980.652$ \\
\hline 10 & HELG & 2017.5 & $3,706,067.427$ & $513,803.616$ & $5,148,174.316$ \\
\hline 11 & HOFJ & 2017.5 & $3,994,171.525$ & $839,948.492$ & $4,885,561.275$ \\
\hline 12 & ISTA* & 2015.3 & $4,208,830.634$ & $2,334,849.953$ & $4,171,267.101$ \\
\hline 13 & KARL & 2017.5 & $4,146,524.604$ & $613,137.781$ & $4,791,517.012$ \\
\hline 14 & LDB2* & 2017.8 & $3,798,345.221$ & $955,552.795$ & $5,017,221.581$ \\
\hline 15 & LEIJ & 2017.5 & $3,898,736.643$ & $855,344.987$ & $4,958,372.290$ \\
\hline 16 & RANT** & 2016.9 & $3,645,376.719$ & $531,201.660$ & $5,189,296.766$ \\
\hline 17 & SAS2* & 2016.3 & $3,606,365.016$ & $875,342.546$ & $5,170,000.000$ \\
\hline 18 & WARN & 2017.5 & $3,658,786.060$ & $784,470.622$ & $5,147,870.445$ \\
\hline 19 & WRLG* & 2016.0 & $4,075,565.218$ & $931,610.273$ & $4,801,620.495$ \\
\hline
\end{tabular}
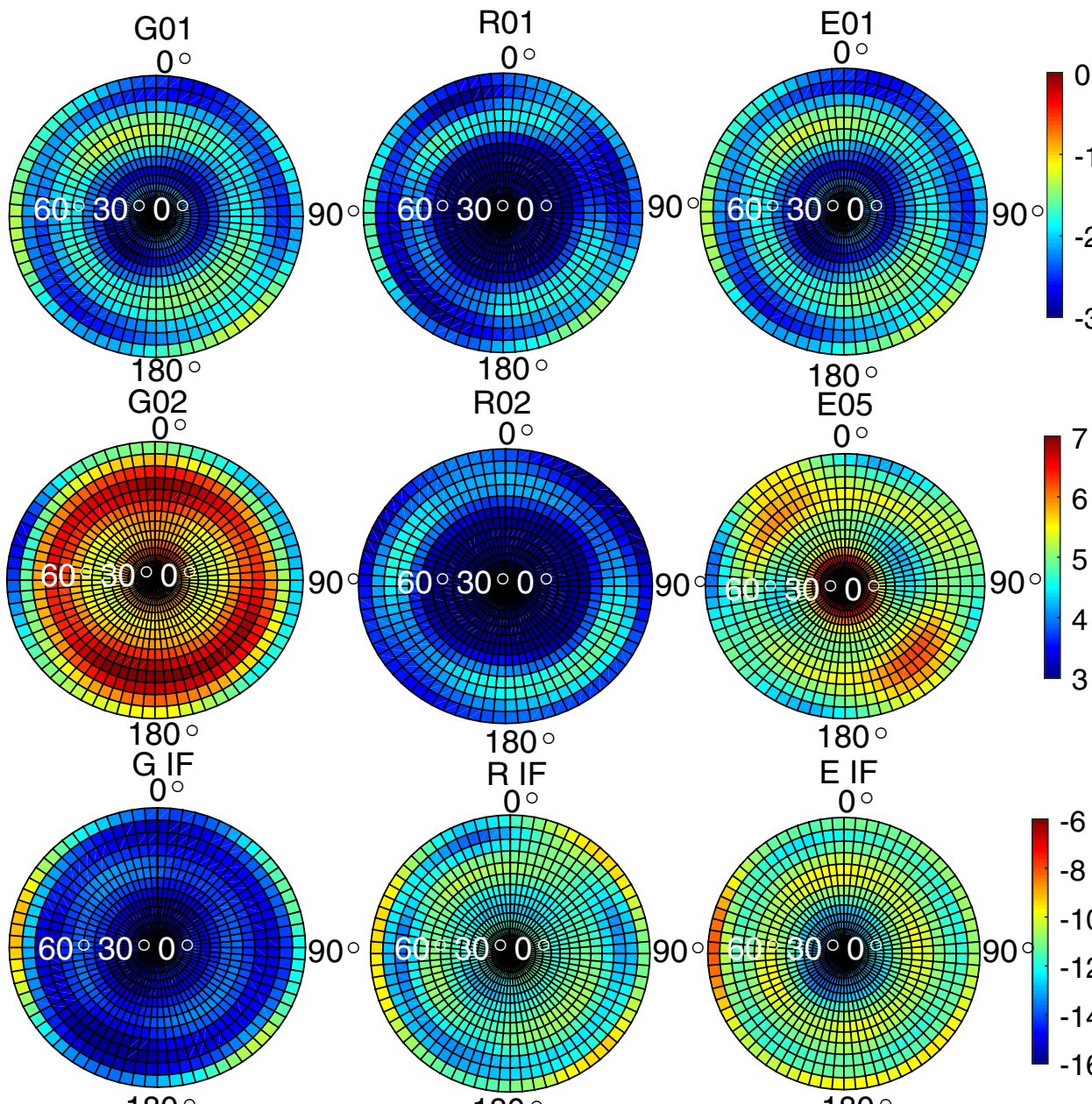

$180^{\circ}$
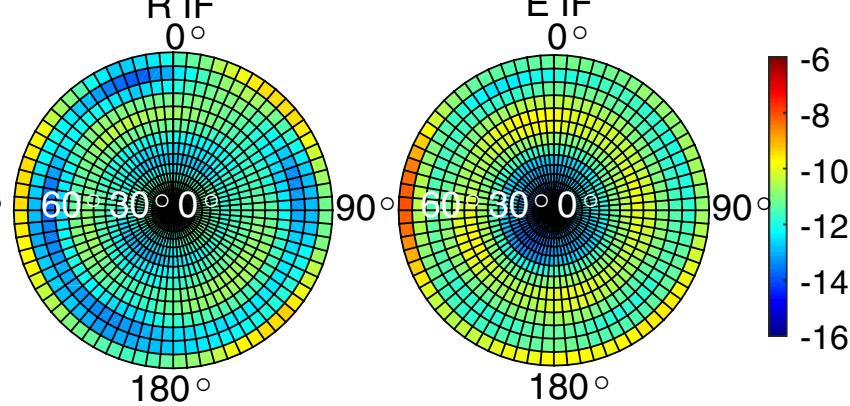
Fig. 3 Azimuth and elevationdependent PCC differences (dPCC) obtained by comparison of chamber and robot calibration results for LEIAR25.R4 LEIT antenna at station HELG. The units are $\mathrm{mm}$
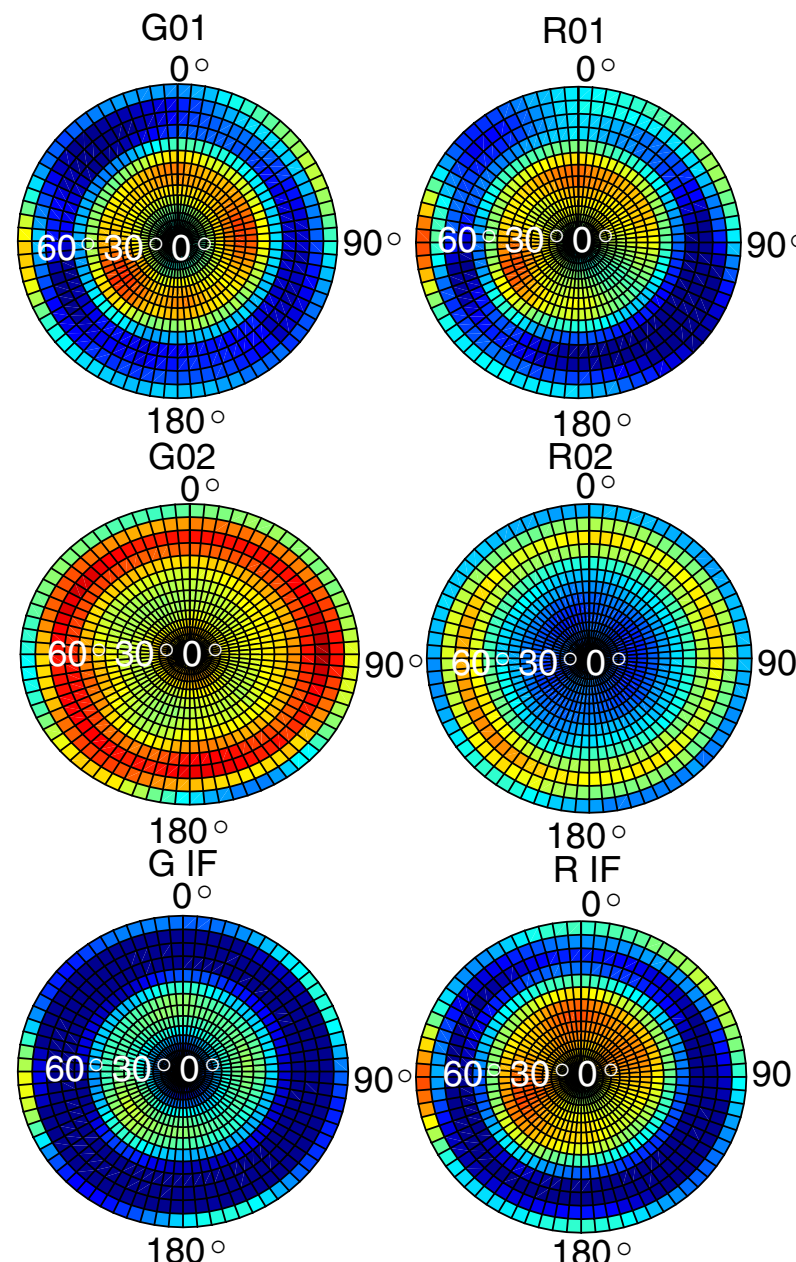

E01

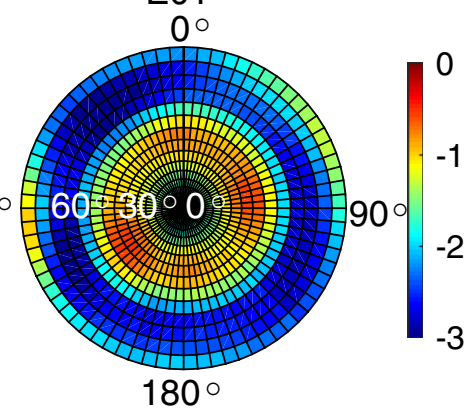

$\mathrm{RO2}$
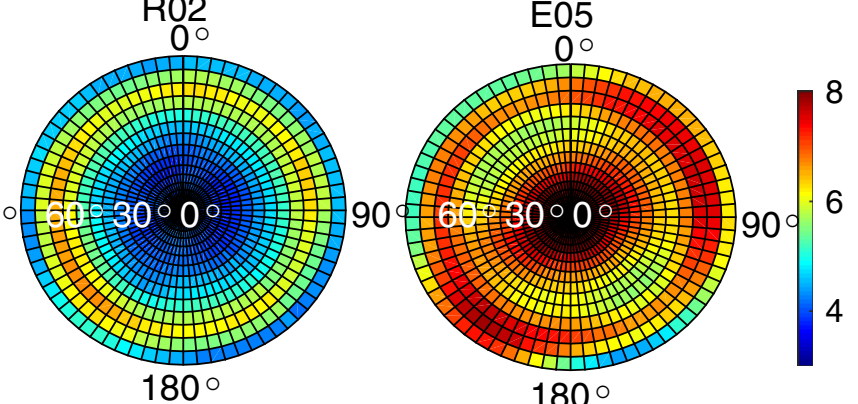

$\mathrm{R}$ IF
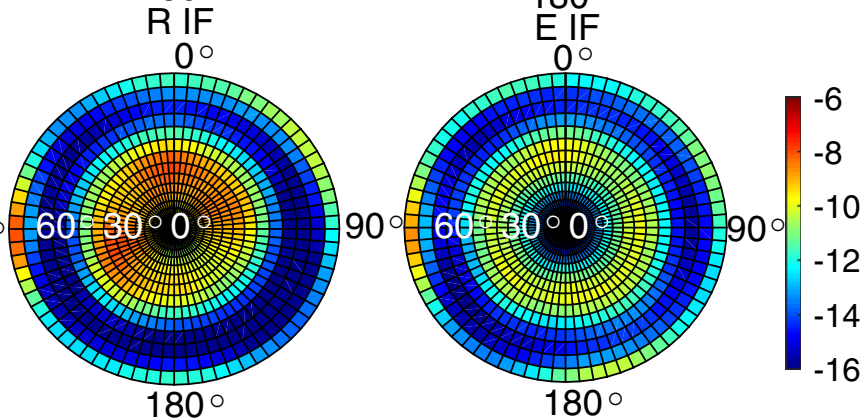

$180^{\circ}$
1 (Altamimi 2018) and compared with each other, as well as with the reference coordinates from C2010 cumulative EPN solution (Table 3). Since not all the stations involved are class A EPN stations, it was not possible to obtain coordinates expressed in the measurement epoch for a few stations, due to the lack of velocities. At class A EPN stations, the GNSS observations are carried out over a long time span. Many years of observations made it possible to determine the position of the station as well as its velocity with high accuracy. However, as the intraplate velocities in ETRF2014 are rather small, class B station coordinates, without velocities, can still be considered as reference coordinates. These stations are marked with * in Table 3.

\section{PCC model comparison}

Previous research on PCC models indicated that transitions from different types of correction models, e.g., from relative to absolute or from mean to individual, cause noticeable changes in the position components (Baire et al. 2013; Dawidowicz and Krzan 2016). In this study, the influence of differences between PCC models derived using a robot (GEO++) and chamber (IGG) methods on GNSS-derived position time series is assessed. First, the differences between PCC obtained with the two methods were analyzed. It must be noted that for the field robot calibration of Galileo E5, the PCC pattern is adopted from GPS L2 frequency. Since L2 and E5 differ in carrier frequency, using GPS L2 calibration for Galileo E5 may cause some discrepancies in the solutions. The differences (dPCC) for the tested antennas for the anechoic chamber and the absolute field robot calibration techniques are presented in Figs. 2, 3 and 4.

Analyzing Figs. 2 and 3, it can be seen that the differences reach up to $4 \mathrm{~mm}$ for $\mathrm{L} 1$ frequency, over $10 \mathrm{~mm}$ for the $\mathrm{L} 2$ frequency and even over $20 \mathrm{~mm}$ for the IF linear combination. It can be observed that the differences are primarily the function of the zenith angle. This applies to all GPS, GLONASS and Galileo solutions obtained for both L1 and L2/E5 frequencies as well as to their IF linear combinations. The dependence of the $\mathrm{dPCC}$ on the azimuth is also noticeable; within the same zenith angle, the differences can reach up to $3 \mathrm{~mm}$ in the case of L1 and L2 frequencies and over $5 \mathrm{~mm}$ for IF. 

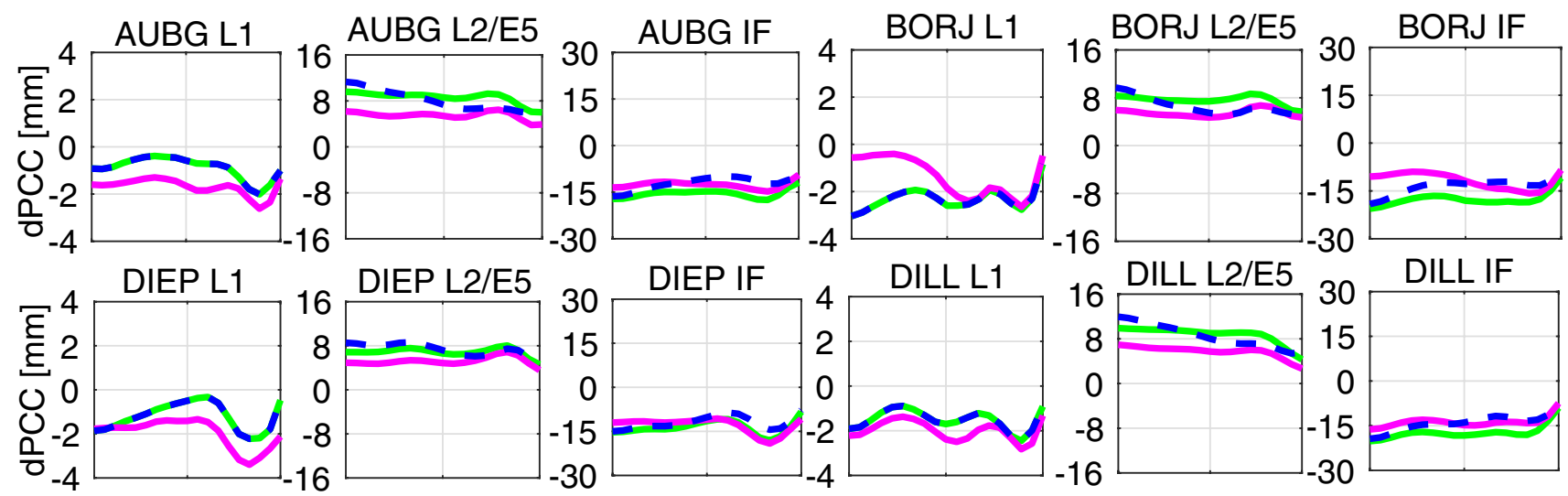

DILL L1

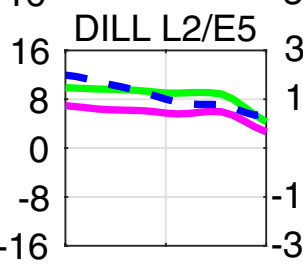

DILL IF
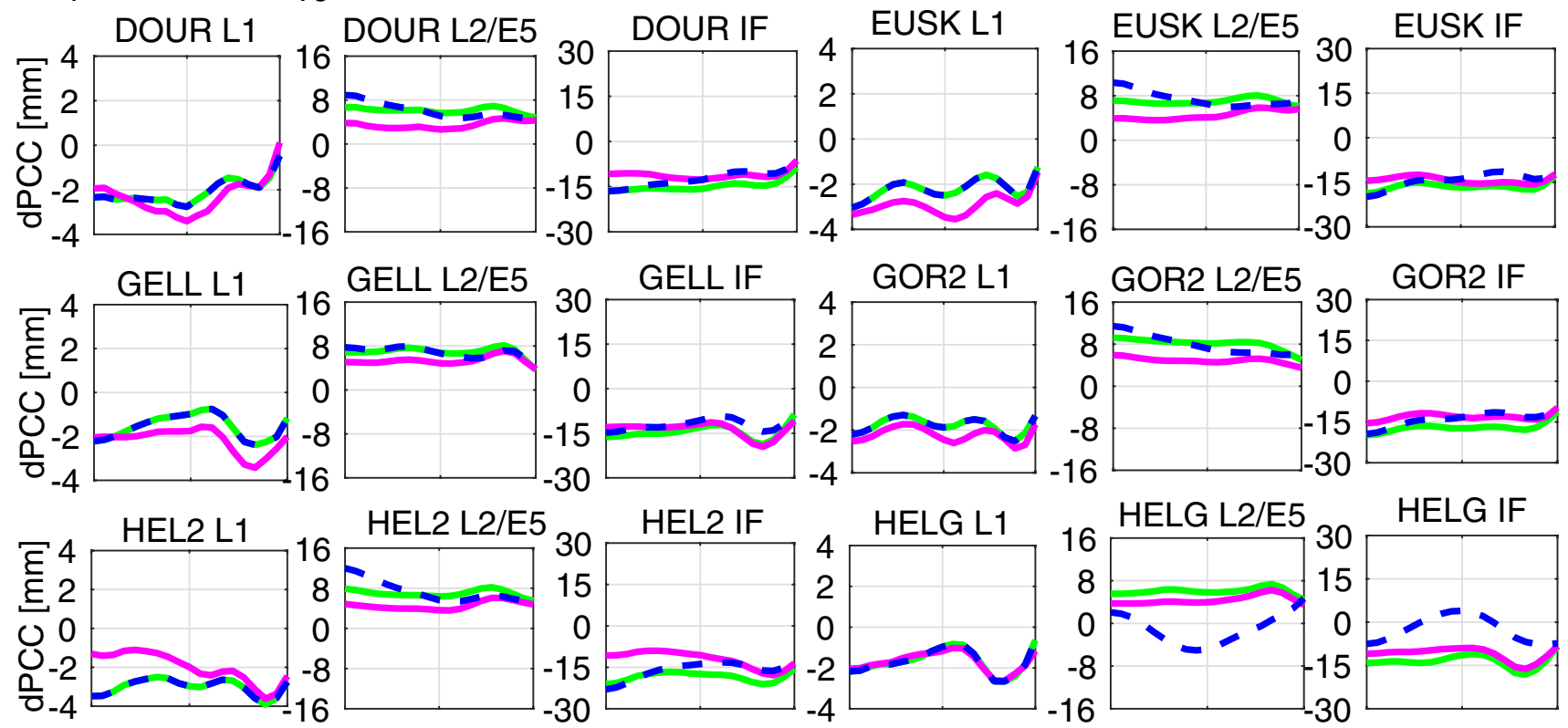

Fig. 4 PCC differences obtained by comparison of chamber and robot calibration patterns as a function of zenith angle only

Figure 4 shows the dependence of dPCC on the zenith angle only. In this case, values taken from the first row of the PCV pattern in the ANTEX files are independent of the azimuth of the received GNSS signals. At first glance, a similar shape of the plots for all three systems for L1 and IF is noticeable. The situation is different for the L2/E5 signal. The adaptation of the corrections from L2 GPS for E5 Galileo causes greater differences as compared to the GPS and GLONASS corrections. In addition, the largest differences for E5 signals are at the zenith, and they can exceed even $10 \mathrm{~mm}$.

\section{Differences in daily station position time series}

For the purpose of analyses, the daily coordinate time series covering 365 days of 2017 are studied. The results allow analyzing the stability and significance of the obtained differences. Since the analysis of time series generally applies topocentric NEU (North, East, Up) coordinates, the time series of the position components were converted to the topocentric system. Time series of the NEU differences relative to the EPN cumulative solution for sample stations DOUR and HELG are presented in Figs. 5, 6, 7 and 8. Table 4 presents the mean NEU differences, obtained from comparing the solutions using the antenna calibration models and the absolute field calibration technique and in the anechoic chamber, for all the analyzed stations.

Analyzing the NEU scattering throughout the year 2017 presented in Figs. 5, 6, 7 and 8, the significantly lower accuracy of the Galileo solution (Fig. 7) is noticeable. This is due to the incomplete constellation of this system, for which the number of simultaneously observed satellites at each station fluctuated during each day from 2 to 6 at the beginning and from 2 to 8 at the end of the analyzed period. As a result, 

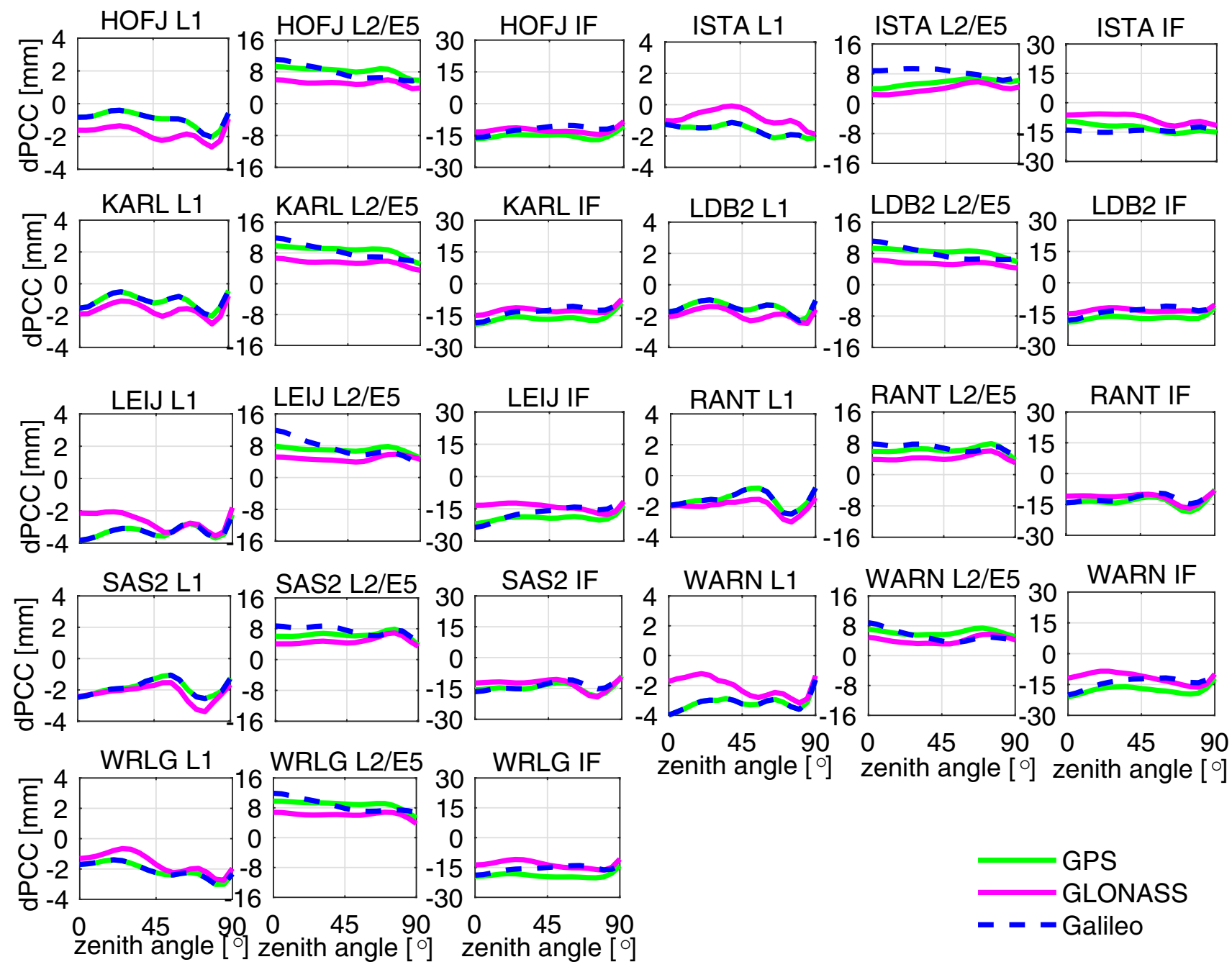

zenith angle [ ${ }^{\circ}$ zenith angle [०] zenith angle [०]

Fig. 4 (continued)

residuals of North and East components reach up to $40 \mathrm{~mm}$ and $20 \mathrm{~mm}$, respectively. In the case of the Galileo-derived Up component, the residuals often exceed $50 \mathrm{~mm}$ and are characterized by systematic underestimation of the determined value.

Considering the GPS, GLONASS and GNSS solutions (Figs. 5, 6 and 8), we see that Easting is characterized by the highest repeatability, rarely exceeding the threshold of $\pm 5 \mathrm{~mm}$ for all solutions. The North component seems to be slightly less precise, indicating the differences from reference value close to $\pm 10 \mathrm{~mm}$. For Up component, the discrepancies throughout the year are much higher and exceed $\pm 20 \mathrm{~mm}$. In this case, also the highest divergence between robot and chamber calibration occurred.

Analyzing the results presented in Table 4, we see that for the horizontal coordinates, the discrepancies between chamber and robot calibrations solutions are small, exceeding $2 \mathrm{~mm}$ only at station GOR2 for solutions utilizing signals from GLONASS. The average deviations between chamber and robot calibrations solutions do not exceed $0.7 \mathrm{~mm}$ for Northing and $0.5 \mathrm{~mm}$ for Easting for all solutions. However, the differences for the Up component are significant and they exceed $\pm 10 \mathrm{~mm}$ in some cases. The average deviation in Up component equals $2.8-4.8 \mathrm{~mm}$. For the GLONASS solution, there is a tendency to overestimate heights when using calibration from the robot, while for Galileo, the dependence seems to be reversed. Among the stations analyzed, there are stations where, according to the IAG Sub-Commission for European Reference Frame (EUREF) recommendations, absolute chamber antenna models should be used (Bruyninx and Legrand 2018). These stations are marked with ** in Table 4.

Figure 9 presents standard deviations (STD) of NEU differences between robot and chamber calibration-based solutions as a function of the absolute value of the offset. In the 

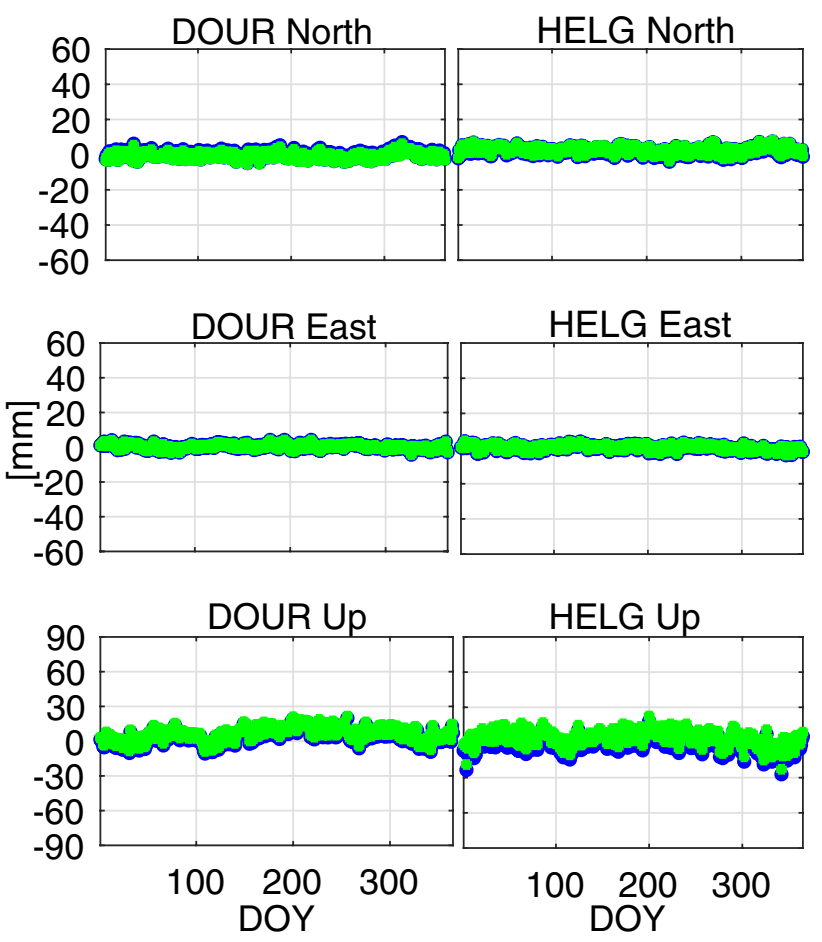

- Robot - Chamber

Fig. 5 North, East and Up position component time series obtained in solutions with the chamber and robot-derived PCC (GPS daily processing)

case of the GPS solution, the STD, which indicates solution repeatability, is significantly lower than the absolute offset and rarely exceeds $0.1 \mathrm{~mm}$ for horizontal coordinates and $0.5 \mathrm{~mm}$ for Up component. Similar results are achieved for GNSS solutions, for which only STD for Up component has risen to about $1 \mathrm{~mm}$. The GLONASS STD values are higher, reaching up to $5 \mathrm{~mm}$ horizontally and up to $1 \mathrm{~mm}$ vertically in some cases. The highest values are recorded for the Galileo solution, where STDs for Northing are in the range of 0.3-0.8 mm, Easting 0.2-0.5 mm and Up 0.6-3.0 mm.

Baire et al. (2013) assumed that the obtained position component differences are statistically significant when their absolute values exceed three times the standard deviation. Following this assumption, we can conclude that differences in obtained results caused by differences in PCC models are statistically significant for $74 \%$ of determined differences for the North component, $68 \%$ for the East component and $84 \%$ for the Up component referring to GPS-only solution. This solution provided the best overall results. In the case of GLONASS-only solutions, the respective values are 63\%, 58\% and $68 \%$. For Galileo solution, characterized by larger result discrepancy (Fig. 9), 10\% of determined differences for the North, 26\% for the East and 74\% for the Up components can be considered significant. Finally, for GNSS solution, these values
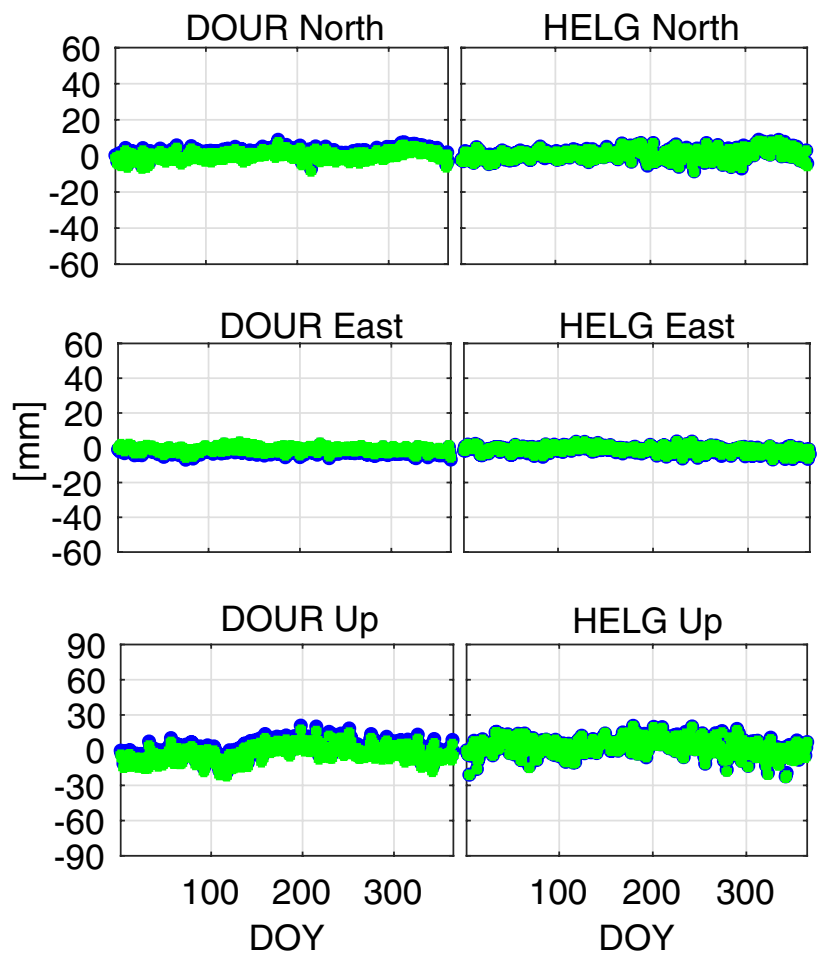

- Robot Chamber

Fig. 6 North, East and Up position component time series obtained in solutions with the chamber and robot-derived PCC (GLONASS daily processing)

amounted to $68 \%, 53 \%$ and $74 \%$. This shows that for analyzed time span, the addition of low number Galileo satellites to the GNSS solution slightly decreases its accuracy.

\section{Compatibility of the results with the cumulative EPN solution}

Table 5 presents the root mean square (RMS) of differences between the estimated and reference coordinates from the cumulative EPN solution. Being in line with previous analyses, the estimated coordinates from GPS, GLONASS and GNSS solutions are much closer to the reference values than results from Galileo. Excluding the ISTA station for which the reference coordinates seem to be inconsistent with our results, the average respective RMS for Northing and Easting is close to $2.0-3.5 \mathrm{~mm}$ in the GPS, GLONASS and GNSS solutions. The Up component RMSs for these systems are close to 7-8 $\mathrm{mm}$. For the Galileo solution, these values equal $18.6 \mathrm{~mm}, 11.0 \mathrm{~mm}$ and $28.5-32.7 \mathrm{~mm}$ for Northing, Easting and Up, respectively.

The large discrepancy between the coordinates from the cumulative EPN solution and those obtained at the ISTA station is most likely due to several factors. The biggest 


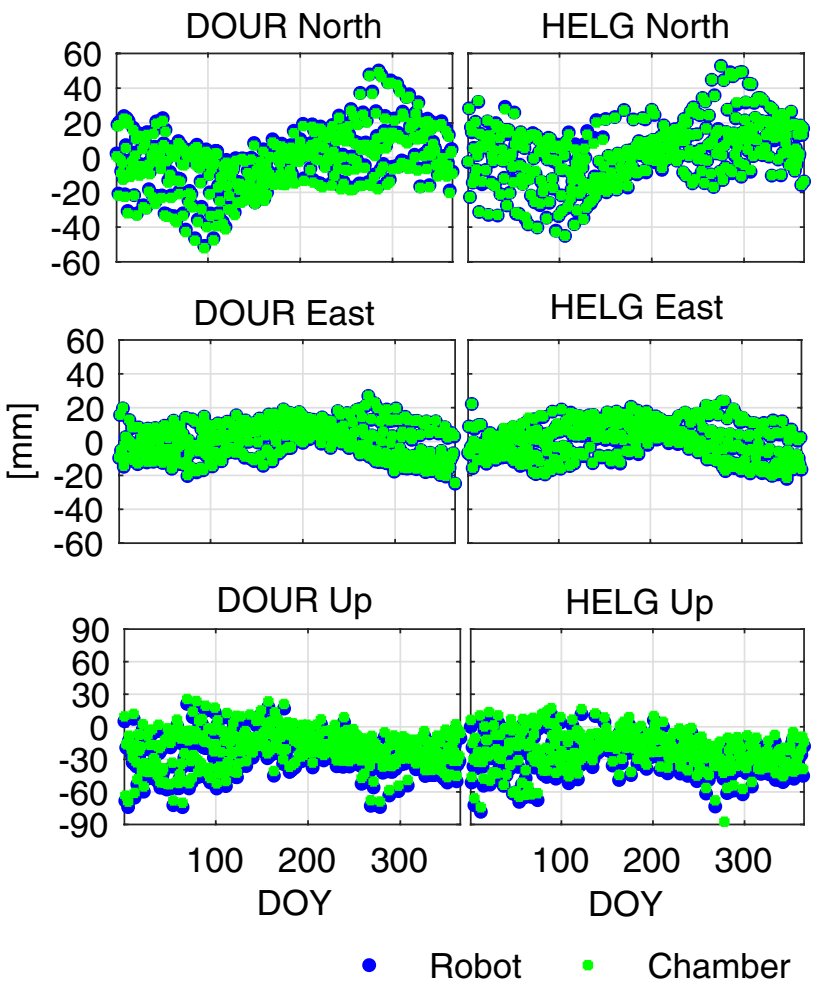

Fig. 7 North, East and Up position component time series obtained in solutions with the chamber and robot-derived PCC (Galileo daily processing)

influence is surely the change in the antenna model, which took place in the middle of 2016, thus after the reference epoch for this station coordinates. Moreover, the influence on coordinate differences has a 2-year period of separation between the measurement epoch and the reference epoch (Table 3). Station ISTA is a class B EPN station; therefore, it has no determined velocities in ETRS. However, in Zahran and Radwan (2012), it can be found that intraplate velocities in this region reach up to $2 \mathrm{~cm} / \mathrm{y}$ in the horizontal plane. This is also confirmed by the analysis of the weekly EPN solutions from 2017, which are consistent with the results obtained in this study.

Considering the differences between RMS obtained from the robot and chamber calibration-based solutions, one can notice that a significant advantage of one of the solutions is revealed primarily in the Up determinations. In the set of stations with priority given by EPN to the chamber model, the advantage of this calibration solution in height determination exceeds $5 \mathrm{~mm}$ for GPS and GLONASS solution for ISTA station and is close to $3 \mathrm{~mm}$ for GPS at WRLG. For other stations, the advantage of the robot solution occurs in a few cases: for the GPS variant at DIEP $(3.0 \mathrm{~mm})$ and GELL $(5.3 \mathrm{~mm})$, for GLONASS at BORJ $(4.2 \mathrm{~mm})$ and for Galileo at most stations where the difference in RMS exceeds even $8 \mathrm{~mm}$ (DIEP). In the case of horizontal coordinates, only

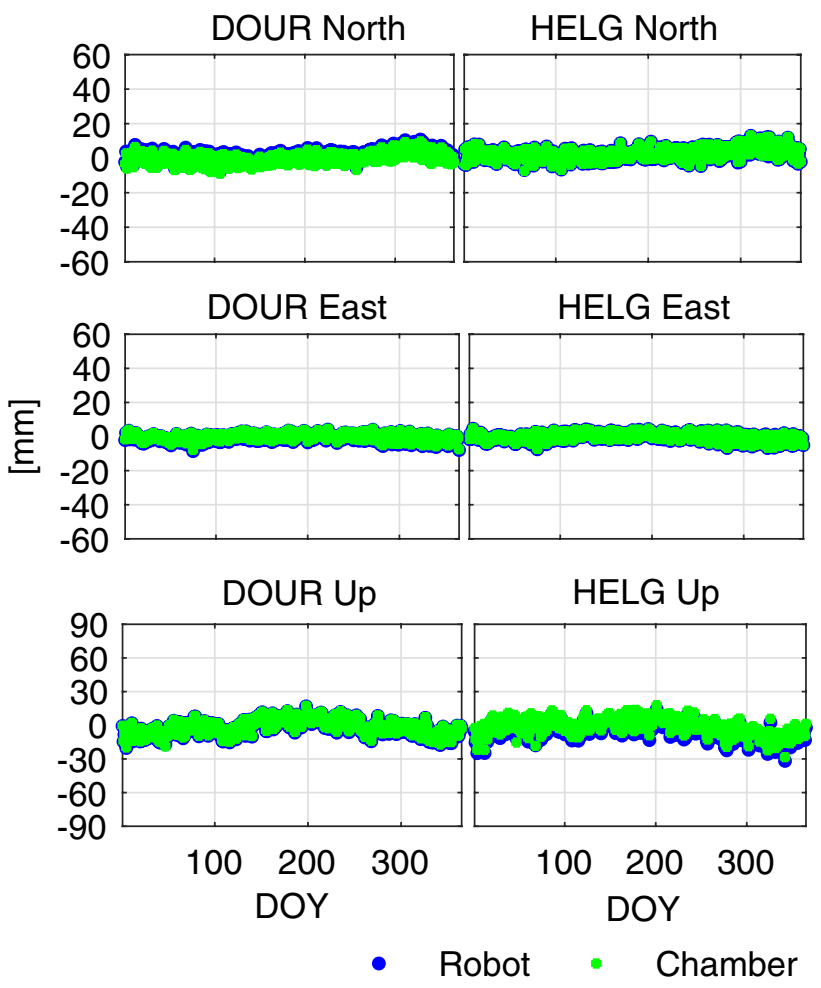

Fig. 8 North, East and Up position component time series obtained in solutions with the chamber and robot-derived PCC (GNSS daily processing)

the station HEL2 shows a significant advantage of the robot solution, exceeding $1 \mathrm{~mm}$ RMS difference for the GLONASS solution.

\section{Conclusions}

The aim of the study was to analyze the differences in the antenna calibration models and their impact on the accuracy of position derived using various GNSS. Two types of antenna calibration models were analyzed: (1) the absolute robot field calibration and (2) the anechoic chamber calibration. The PPP position time series of 19 EPN stations equipped with LEICA AR25 antennas were analyzed for GPS, GLONASS, Galileo and combined GPS + GLONASS + Galileo GNSS signals. Satellite observations were post-processed using the NAPEOS software.

Comparison of PCC models obtained from the absolute field calibration and the calibration in the anechoic chamber revealed differences of up to $20 \mathrm{~mm}$ in the case of the IF combination. For L1 and L2 frequencies, these differences are visibly smaller, but their maximum values are close to $5 \mathrm{~mm}$ for $\mathrm{L} 1$ and can exceed $10 \mathrm{~mm}$ for L2 signals. These differences should be considered significant if millimeter 
Table 4 Mean position components differences between daily solutions obtained with the robot and chamber-derived PCC models

\begin{tabular}{|c|c|c|c|c|c|c|c|c|c|c|c|c|}
\hline \multirow[t]{3}{*}{ Station } & \multicolumn{12}{|c|}{ Mean position component differences (CHAMBER-ROBOT) (mm) } \\
\hline & \multicolumn{3}{|l|}{ GPS } & \multicolumn{3}{|c|}{ GLONASS } & \multicolumn{3}{|c|}{ Galileo } & \multicolumn{3}{|l|}{ GNSS } \\
\hline & North & East & Up & North & East & Up & North & East & Up & North & East & Up \\
\hline AUBG & -0.3 & -0.6 & -1.9 & -0.1 & -0.3 & -5.0 & -0.1 & 0.5 & 0.6 & -0.2 & -0.3 & -2.3 \\
\hline BORJ & -0.5 & -0.3 & -1.8 & 0.4 & 0.4 & -12.4 & -1.0 & -0.2 & 3.4 & -0.2 & 0.0 & -3.8 \\
\hline DIEP & -0.3 & 0.4 & 8.5 & -0.2 & 0.4 & -0.9 & -0.2 & 0.9 & 11.4 & -0.2 & 0.5 & 5.8 \\
\hline DILL & -1.1 & 0.3 & 0.3 & -2.0 & 0.5 & -2.1 & -0.3 & 0.1 & 2.1 & -1.5 & 0.4 & 0.1 \\
\hline DOUR** & -0.8 & -0.1 & 1.8 & -1.4 & 1.1 & -3.6 & -1.3 & 0.4 & 4.7 & -1.2 & 0.5 & 0.6 \\
\hline EUSK & 0.2 & 0.3 & -0.1 & 0.4 & 0.2 & -6.7 & 0.1 & 1.1 & 3.6 & 0.3 & 0.4 & -1.4 \\
\hline GELL & 0.4 & 0.9 & 7.1 & 0.5 & 0.2 & 1.5 & 0.9 & 1.2 & 9.8 & 0.5 & 0.6 & 5.6 \\
\hline GOR2 & -1.4 & 0.1 & 2.4 & -2.4 & 0.2 & -0.3 & -0.7 & 0.0 & 5.1 & -1.9 & 0.1 & 2.1 \\
\hline HEL2 & 1.2 & 1.2 & 2.8 & -0.4 & 1.8 & -3.9 & 1.5 & 1.2 & 9.1 & 0.4 & 1.4 & 1.5 \\
\hline HELG & 0.5 & 0.2 & 4.2 & -0.2 & 0.2 & -0.6 & 0.1 & 0.4 & 4.9 & 0.1 & 0.2 & 3.3 \\
\hline HOFJ & -0.1 & -0.5 & -1.7 & 0.4 & 0.4 & -5.4 & -0.1 & 0.5 & 1.3 & 0.2 & 0.0 & -2.4 \\
\hline ISTA** & 0.2 & -0.1 & -9.6 & 0.5 & 0.2 & -11.6 & 0.0 & 0.0 & -4.3 & 0.4 & 0.1 & -9.7 \\
\hline KARL & -1.2 & 0.3 & 0.3 & -1.7 & 0.6 & -2.3 & -0.6 & 0.0 & 2.5 & -1.4 & 0.4 & 0.3 \\
\hline LDB2 & -1.3 & 0.6 & 0.7 & -1.5 & 0.4 & -2.3 & -0.3 & 0.1 & 3.5 & -1.4 & 0.4 & 0.3 \\
\hline LEIJ & 0.3 & -0.4 & 3.1 & 0.2 & -1.0 & -4.0 & 0.9 & -0.7 & 7.6 & 0.2 & -0.6 & 2.2 \\
\hline RANT & 0.1 & -0.2 & 3.5 & 0.4 & 0.1 & -1.6 & 0.4 & 0.3 & 4.6 & 0.2 & 0.0 & 2.6 \\
\hline SAS2 & -0.2 & -0.1 & 5.6 & 0.2 & 0.0 & -0.5 & -0.1 & 0.4 & 6.3 & 0.0 & 0.0 & 4.3 \\
\hline WARN & 1.0 & 0.1 & 1.6 & -0.3 & 0.2 & -6.7 & 0.6 & 0.0 & 4.3 & 0.2 & 0.1 & -0.5 \\
\hline WRLG** & 0.5 & -0.6 & -4.8 & 0.5 & -0.6 & -8.9 & -0.5 & 0.3 & -1.5 & 0.5 & -0.4 & -5.2 \\
\hline Average deviation & 0.6 & 0.4 & 3.2 & 0.7 & 0.5 & 4.2 & 0.5 & 0.4 & 4.8 & 0.6 & 0.3 & 2.8 \\
\hline
\end{tabular}

Significant differences over $2 \mathrm{~mm}$ horizontally and $5 \mathrm{~mm}$ vertically are in bold. Stations at which chamber model is recommended are denoted by $* *$ accuracy of the position components is expected. For Galileo E5 signals, the most significant dPCC occurred at zenith in many cases, which is caused by adapting L2 corrections in case of robot calibrations. This may result in significant bias in position determination using Galileo signals and robot calibrations.

In analyzing the results obtained for daily solution time series based on GPS, GLONASS and GNSS data, for the North component, the differences between the obtained and reference coordinates were below $\pm 10 \mathrm{~mm}$, for the East component they do not exceed $\pm 5 \mathrm{~mm}$, and for the vertical component they reached up to $\pm 20 \mathrm{~mm}$. However, for Galileo the discrepancies were much higher reaching up to $40 \mathrm{~mm}, 20 \mathrm{~mm}$ and $50 \mathrm{~mm}$ for Northing, Easting and Up, respectively. The poor accuracy associated with the Galileo solution is caused by an unsatisfactory number of satellites in the period under investigation, as well as the adoption of GPS L2 PCC pattern to correct Galileo E5 observations in case of robot calibrations.

The differences of coordinates, obtained from averaging daily results from robot and chamber calibration solutions, rarely exceeded $\pm 2 \mathrm{~mm}$ in horizontal components and $\pm 10 \mathrm{~mm}$ in heights. Average deviations for GPS, GLONASS, Galileo and GNSS solutions proved very similar, being close to $0.6 \mathrm{~mm}, 0.5 \mathrm{~mm}$ and $4.8 \mathrm{~mm}$ for Northing, Easting and Up, respectively.

When comparing the results from both types of calibrations with the reference coordinates from the cumulative EPN solution, a noticeable difference in the solutions occurred primarily in the case of height determinations. For stations ISTA and WRLG, with priority given to chamber calibration according to EPN recommendations, the height component RMS of the solution utilizing this calibration was smaller, in the range of 3-5 mm. Height RMS difference, exceeding even $8 \mathrm{~mm}$, in favor of chamber calibration solution also occurred at most stations in the Galileo solutions. In the set of stations with priority given to robot calibration, the significant predominance of this type of calibration, exceeding $3 \mathrm{~mm}$ RMS difference, occurred at three stations (DIEP, GELL and BORJ) in the GPS and GLONASS solutions. For horizontal coordinates, however, only two stations (HEL2 and GOR2) revealed the noticeable advantage of any solution, exceeding the threshold of $1 \mathrm{~mm}$ in favor of the solution utilizing the calibration from the robot in the GLONASS solution. For other stations, the differences between solutions were below $1 \mathrm{~mm}$, which means that differences between PCC patterns do not affect the horizontal coordinates significantly. 
Fig. 9 Standard deviations (STD) of estimated position differences in comparison with the absolute values of the obtained differences for three position components (daily processing)

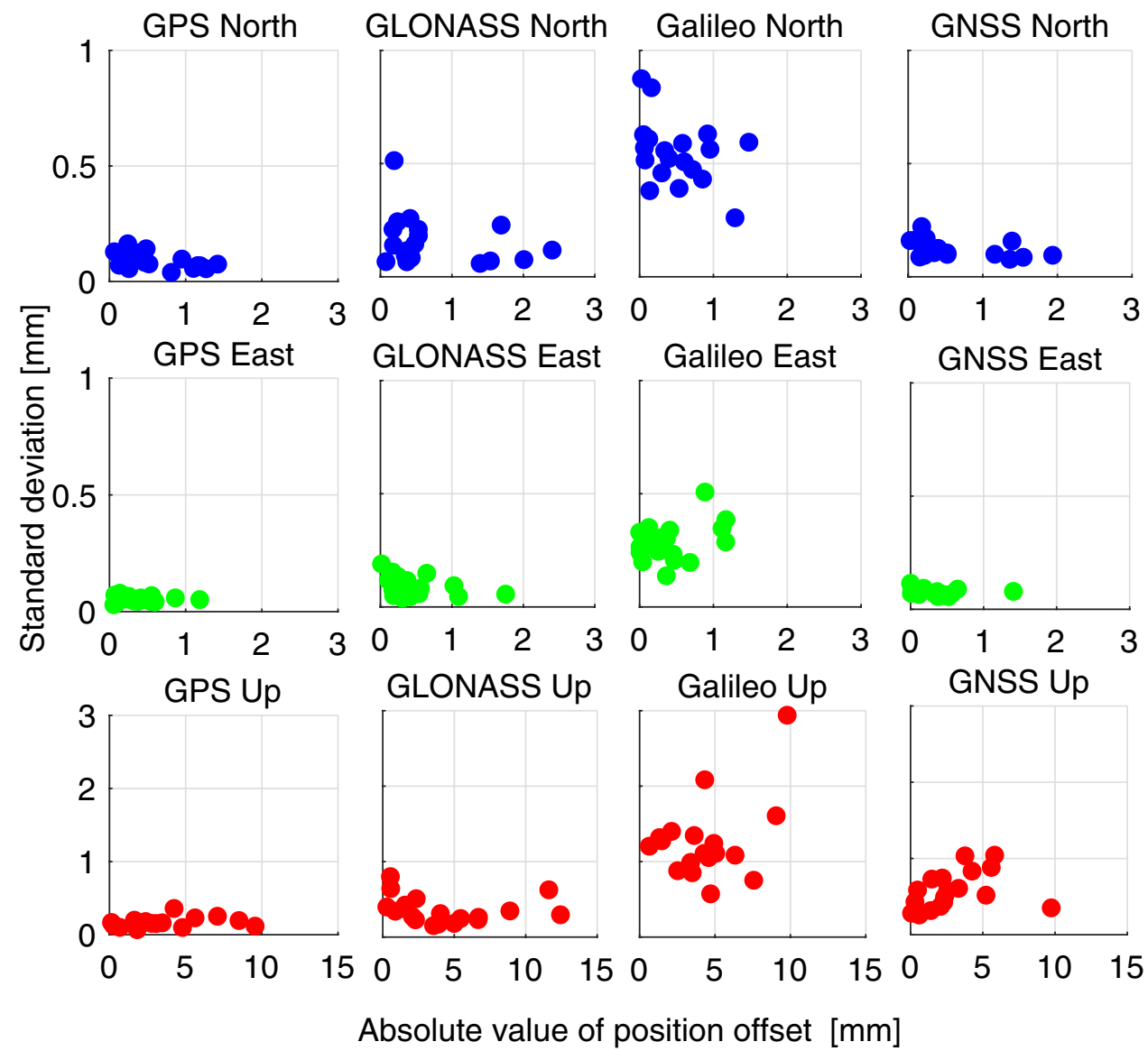

Table 5 RMS of position differences obtained with the robot and chamber-derived PCC models

\begin{tabular}{|c|c|c|c|c|c|c|c|c|c|c|c|c|}
\hline \multirow[t]{3}{*}{ Station } & \multicolumn{12}{|c|}{ RMS of position differences (ROBOT/CHAMBER) (mm) } \\
\hline & \multicolumn{3}{|l|}{ GPS } & \multicolumn{3}{|l|}{ GLONASS } & \multicolumn{3}{|l|}{ Galileo } & \multicolumn{3}{|l|}{ GNSS } \\
\hline & North & East & Up & North & East & Up & North & East & Up & North & East & Up \\
\hline AUBG & $3.3 / 3.6$ & $2.2 / 1.8$ & $6.1 / 5.1$ & $2.4 / 2.4$ & $3.2 / 3.5$ & $7.0 / 6.6$ & $18.5 / 18.5$ & $10.6 / 10.7$ & $38.6 / 38.0$ & $3.0 / 3.1$ & $2.0 / 2.1$ & $6.0 / 6.9$ \\
\hline BORJ & $2.2 / 2.3$ & $2.2 / 2.0$ & $6.2 / 6.5$ & $3.0 / 2.8$ & $2.3 / 2.2$ & 7.7/11.9 & $17.8 / 18.0$ & $10.8 / 10.8$ & $30.5 / 27.5$ & $3.5 / 3.5$ & $2.9 / 2.9$ & $8.7 / 11.2$ \\
\hline DIEP & $2.5 / 2.4$ & $2.0 / 2.3$ & $5.6 / 9.6$ & $2.6 / 2.6$ & $1.8 / 1.7$ & $6.8 / 6.5$ & 18.7/18.7 & $10.7 / 10.8$ & $35.7 / 26.9$ & $3.3 / 3.2$ & $2.2 / 2.2$ & $7.1 / 6.3$ \\
\hline DILL & $2.3 / 2.2$ & $2.1 / 2.3$ & $8.9 / 9.1$ & $2.7 / 3.0$ & $1.9 / 1.7$ & $7.2 / 8.2$ & $19.7 / 19.8$ & $11.5 / 11.5$ & $35.8 / 34.3$ & $3.1 / 3.0$ & $2.3 / 2.4$ & $6.2 / 6.3$ \\
\hline DOUR** & $1.9 / 2.1$ & $1.4 / 1.4$ & 7.4/8.6 & $2.8 / 2.4$ & $2.5 / 1.8$ & $6.8 / 7.4$ & $17.0 / 17.1$ & $10.1 / 10.1$ & $29.6 / 25.9$ & $3.3 / 3.1$ & $2.4 / 2.2$ & $7.0 / 6.9$ \\
\hline EUSK & $2.6 / 2.7$ & $2.7 / 2.9$ & $8.1 / 8.1$ & $2.6 / 2.8$ & $1.7 / 1.8$ & 7.3/9.0 & $19.2 / 19.1$ & $11.2 / 11.5$ & $34.6 / 31.8$ & $3.2 / 3.3$ & $2.5 / 2.6$ & $6.8 / 7.3$ \\
\hline GELL & $2.4 / 2.6$ & $2.8 / 2.1$ & $6.9 / 12.2$ & $2.5 / 2.7$ & $1.7 / 1.8$ & $6.4 / 6.6$ & 19.6/19.4 & $10.9 / 10.8$ & $30.4 / 24.1$ & $3.2 / 3.5$ & $2.4 / 2.2$ & $6.7 / 7.4$ \\
\hline GOR2 & $2.3 / 2.7$ & $1.7 / 1.7$ & $6.1 / 7.7$ & 2.3/3.5 & $1.7 / 1.8$ & $6.1 / 6.1$ & $20.2 / 20.3$ & 11.6/11.6 & $32.1 / 28.3$ & $2.7 / 3.2$ & $2.3 / 2.3$ & $6.5 / 5.8$ \\
\hline HEL2 & $3.3 / 4.2$ & $1.7 / 2.5$ & $6.8 / 8.3$ & $2.7 / 2.5$ & $1.5 / 2.6$ & $6.9 / 7.4$ & 18.9/19.0 & $11.0 / 11.2$ & $34.6 / 27.4$ & $3.6 / 3.9$ & $2.2 / 2.8$ & $7.4 / 7.1$ \\
\hline HELG & $2.8 / 3.2$ & $1.5 / 1.6$ & $6.3 / 7.5$ & $3.0 / 3.0$ & $2.2 / 2.1$ & 7.9/7.7 & 17.7/17.6 & $10.4 / 10.4$ & $31.3 / 27.3$ & $4.2 / 4.3$ & $2.4 / 2.4$ & $8.9 / 7.6$ \\
\hline $\mathrm{HOFJ}$ & $2.4 / 2.4$ & 4.4/3.9 & $6.2 / 6.7$ & $2.6 / 2.5$ & $2.6 / 2.4$ & $7.6 / 7.4$ & $19.3 / 19.4$ & $11.1 / 11.2$ & $35.3 / 34.2$ & $2.8 / 2.8$ & $2.3 / 2.3$ & $7.7 / 9.0$ \\
\hline ISTA** & $62.8 / 63.0$ & $37.5 / 37.6$ & 14.6/8.3 & $62.2 / 62.7$ & $40.3 / 40.0$ & 13.8/8.4 & $64.9 / 64.9$ & $38.7 / 38.7$ & $36.9 / 38.7$ & $63.1 / 63.5$ & $38.8 / 38.7$ & $10.4 / 8.1$ \\
\hline KARL & $2.4 / 3.2$ & $3.0 / 3.2$ & $6.4 / 6.5$ & $3.3 / 4.2$ & $2.4 / 2.6$ & $8.1 / 8.0$ & 17.6/17.7 & 10.6/10.6 & $29.3 / 27.2$ & $3.6 / 4.0$ & $3.5 / 3.7$ & $8.3 / 8.2$ \\
\hline LDB2 & $3.1 / 2.2$ & $1.8 / 1.8$ & $7.5 / 7.9$ & $2.4 / 2.7$ & $2.0 / 2.3$ & $6.8 / 7.6$ & $19.6 / 19.7$ & $11.5 / 11.5$ & $36.1 / 33.6$ & $3.4 / 2.9$ & $2.4 / 2.5$ & 7.7/7.6 \\
\hline LEIJ & $2.0 / 2.0$ & 1.9/1.7 & $7.1 / 8.9$ & $2.8 / 2.7$ & $1.8 / 2.0$ & $8.2 / 8.2$ & $17.8 / 17.8$ & $10.6 / 10.5$ & 29.2/23.2 & $3.3 / 3.4$ & $2.6 / 2.6$ & 7.9/7.4 \\
\hline RANT & $2.0 / 2.0$ & 1.6/1.6 & $6.0 / 7.0$ & $2.5 / 2.6$ & $2.2 / 2.1$ & $7.2 / 6.9$ & $17.8 / 17.6$ & $10.8 / 10.8$ & $31.6 / 27.7$ & $3.4 / 3.4$ & $2.6 / 2.6$ & $8.7 / 7.5$ \\
\hline SAS2 & $2.2 / 2.3$ & 1.9/1.9 & 7.0/9.7 & $3.0 / 2.9$ & $2.7 / 2.8$ & $9.1 / 8.8$ & $18.1 / 18.1$ & $10.8 / 10.8$ & $29.9 / 24.6$ & $3.8 / 3.8$ & $2.9 / 2.9$ & $8.5 / 7.8$ \\
\hline WARN & $2.1 / 1.9$ & 1.9/1.9 & $5.9 / 6.3$ & $2.6 / 2.4$ & $2.0 / 2.0$ & $6.3 / 9.5$ & 18.0/18.0 & $10.9 / 10.8$ & $31.5 / 27.7$ & $3.3 / 3.4$ & $2.7 / 2.7$ & $8.3 / 8.7$ \\
\hline WRLG** & $2.5 / 2.8$ & $2.3 / 1.9$ & $9.8 / 6.8$ & $2.3 / 2.5$ & $1.9 / 1.8$ & $8.2 / 9.0$ & $18.1 / 18.1$ & 11.5/11.6 & $32.4 / 33.6$ & $3.1 / 3.3$ & $2.7 / 2.5$ & $6.6 / 8.0$ \\
\hline Average & $2.5 / 2.6$ & $2.1 / 2.1$ & $6.9 / 7.9$ & $2.7 / 2.8$ & $2.1 / 2.2$ & $7.3 / 7.9$ & 18.7/18.6 & $10.9 / 11.0$ & $32.7 / 28.5$ & $3.3 / 3.4$ & $2.5 / 2.6$ & $7.5 / 7.6$ \\
\hline RMS*** & & & & & & & & & & & & \\
\hline
\end{tabular}

**Stations with priority given to the chamber model in EPN. ***Station ISTA is excluded from the average 
Acknowledgements We would like to express a very great appreciation for GNSS data provided by the International GNSS Service, EUREF Permanent Network, and the European Space Agency as well as for NAPEOS software made available by ESA. We would also like to extend our thanks to GEO++ GmbH and the University of Bonn for providing open access to their absolute antenna calibrations in EPN.

Data availability Data containing satellite observations used in the study are publicly available on the server: ftp://ftp.epncb.oma.be/pub/ obs. Orbit and clocks products used in the study are publicly available at http://navigation-office.esa.int/products. ANTEX files with antenna calibrations are available at EPN Web site: http://www.epncb.oma.be/ $\mathrm{ftp} /$ station/general/indiv_calibrations/. Processing logs and result files are available from the corresponding author on reasonable request

Open Access This article is licensed under a Creative Commons Attribution 4.0 International License, which permits use, sharing, adaptation, distribution and reproduction in any medium or format, as long as you give appropriate credit to the original author(s) and the source, provide a link to the Creative Commons licence, and indicate if changes were made. The images or other third party material in this article are included in the article's Creative Commons licence, unless indicated otherwise in a credit line to the material. If material is not included in the article's Creative Commons licence and your intended use is not permitted by statutory regulation or exceeds the permitted use, you will need to obtain permission directly from the copyright holder. To view a copy of this licence, visit http://creativecommons.org/licenses/by/4.0/.

\section{References}

Aerts W (2011) Comparison of UniBonn and Geo++ ${ }^{\circledR}$; calibration for LEIAR25.R3 antenna 09300021. Technical report, Royal Observatory of Belgium

Aerts W, Moore M (2013) Comparison of UniBonn and IGS08 antenna type means. White paper, international GNSS serviceantenna working group IGS-AWG. EMail: IGS-AWG-393

Altamimi Z (2018) EUREF technical note 1: relationship and transformation between the international and the European terrestrial reference systems. http://etrs89.ensg.ign.fr/pub/EUREF-TN-1. pdf

Araszkiewicz A, Völksen C (2017) The impact of the antenna phase center models on the coordinates in the EUREF permanent network. GPS Solut 21(2):747-757. https://doi.org/10.1007/s1029 1-016-0564-7

Baire Q, Bruyninx C, Legrand J, Pottiaux E, Aerts W, Defraigne P, Bergeot N, Chevalier JM (2013) Influence of different GPS receiver antenna calibration models on geodetic positioning. GPS Solut 18(4):529-539. https://doi.org/10.1007/s10291-013-0349-1

Bilich A, Mader G (2010) GNSS absolute antenna calibration at the national geodetic survey. In: Proceedings of the ION GNSS 2010. Institute of Navigation, Portland, Oregon, OR, September 21-24, pp 1369-1377

Boehm J, Heinkelmann R, Schuh H (2007) Short note: a global model of pressure and temperature for geodetic applications. J Geodesy 81(10):679-683. https://doi.org/10.1007/s00190-007-0135-3

Bruyninx C, Legrand J (2018) Individual antenna calibrations in the EPN: past, present, and future. In: Proceedings from EUREF2018 symposium, Amsterdam
Dawidowicz K, Krzan G (2016) Analysis of PCC model dependent periodic signals in GLONASS position time series using LombScargle periodogram. Acta Geodyn Geomater 13(3):299-314. https://doi.org/10.13168/AGG.2016.0012

Dilssner F, Seeber G, Wübbena G, Schmitz M (2008) Impact of near-field effects on the GNSS position solution. In: Proceedings of the ION GNSS 2008. Institute of Navigation, Savannah, Georgia, USA, September 16-19, pp 612-624

Görres B, Campbell M, Becker M, Sieme M (2006) Absolute calibration of GPS antennas: laboratory results and comparison with field and robot techniques. GPS Solut 10(2):136-145. https:// doi.org/10.1007/s10291-005-0015-3

IEEE Standard for Definitions of Terms for Antennas (2014). In: IEEE Std 145-2013 (revision of IEEE Std 145-1993), pp 1-50. https://doi.org/10.1109/ieeestd.2014.6758443

Kersten T, Schön S (2016) Receiver antenna phase center models and their impact on geodetic parameters. In: Freymueller JT, Sánchez L (eds) International symposium on earth and environmental sciences for future generations. International association of geodesy symposia, vol. 147. Springer, Cham, pp 253-260

Lyard L, Lefevre L, Letellier T, Francis O (2006) Modelling the global ocean tides: insights from FES2004. Ocean Dyn 56(56):394-415. https://doi.org/10.1007/s10236-006-0086-x

Mader GL (1999) GPS antenna calibration at the national geodetic survey. J Geodesy 3(1):50-58. https://doi.org/10.1007/PL000 12780

Montenbruck O et al (2017) The multi-GNSS experiment (MGEX) of the international GNSS service (IGS) - achievements, prospects and challenges. Adv Space Res 59(7):1671-1697. https:// doi.org/10.1016/j.asr.2017.01.011

Petit G, Luzum B (2010) IERS conventions (2010). Technical report 36, Frankfurt am Main: Verlag des Bundesamts für Kartographie und Geodäsie, 179 pp, ISBN 3-89888-989-6

Rothacher M, Schmid R (2010) ANTEX: the antenna exchange format, version 1.4. ftp://igs.org/pub/station/general/antex14.txt

Rothacher M, Schaer S, Mervart SL, Beutler G (1995) Determination of antenna phase center variations using GPS data. In: Proceedings of the IGS workshop, Potsdam, Germany, May 15-17

Springer TA (2009) NAPEOS-mathematical models and algorithms. Technical note, DOPS-SYS-TN-0100-OPS-GN. http:// hpiers.obspm.fr/combinaison/documentation/articles/NAPEO S_MathModels_Algorithms.pdf

Stępniak K, Wielgosz P, Baryła R (2015) Field tests of L1 phase centre variation models of surveying-grade GPS antennas. Stud Geophys Geod 59(3):394-408. https://doi.org/10.1007/s1120 0-014-0250-6

Wübbena G, Menge F, Schmitz M, Seeber G, Völksen C (1997) A new approach for field calibration of absolute antenna phase center variations. In: Proceedings of the ION GPS-96, Kansas City Convention Center, Kansas City, Missouri, USA, September 16-19, pp 1205-1214

Wübbena G, Schmitz M, Menge F, Böder V, Seeber G (2000) Automated absolute field calibration of GPS antennas in real-time. In: Proceedings of the ION GPS 2000, Salt Palace Convention Center, Salt Lake City, UT, USA, September 19-22, pp 2512-2522

Zahran K, Radwan A (2012) Geodynamics implication of GPS and satellite altimeter and gravity observations to the Eastern Mediterranean. NRIAG J Astron Geophys 1(1):51-60. https://doi. org/10.1016/j.nrjag.2012.11.006 
Publisher's Note Springer Nature remains neutral with regard to jurisdictional claims in published maps and institutional affiliations.

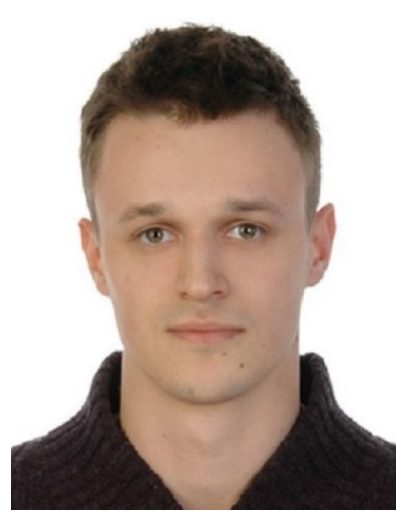

Grzegorz Krzan received his Ph.D. in Satellite Geodesy from the University of Warmia and Mazury in Olsztyn in 2018. His current research involves precise point positioning and GNSS signals interference phenomena. He is a member of the Advanced Methods of GNSS Data Processing Group.

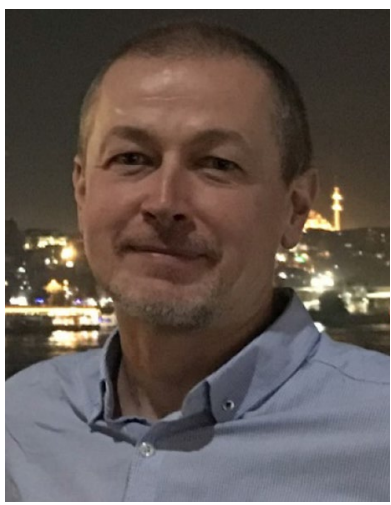

Karol Dawidowicz received his $\mathrm{Ph} . \mathrm{D}$. in Satellite Geodesy from the University of Warmia and Mazury in Olsztyn in 2001. His research interests cover GNSSlevelling, GNSS antenna phase center variations modeling and precise point positioning. He is a member of the Advanced Methods of GNSS Data Processing Group.

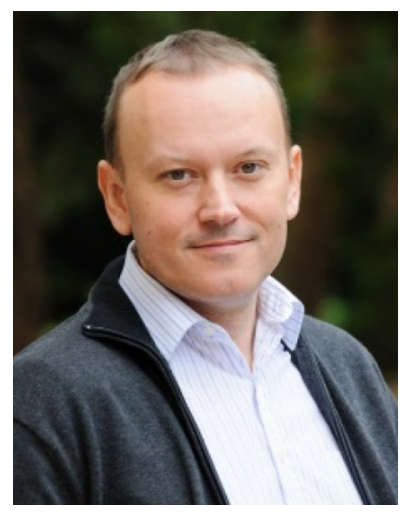

Pawel Wielgosz is a Full Professor at the Faculty of Geodesy, Geospatial and Civil Engineering of the University of Warmia and Mazury in Olsztyn, Poland, where he heads the Advanced Methods of GNSS Data Processing Group. His research interests cover satellite navigation, precise kinematic and static positioning, and also GNSS-based ionosphere and troposphere study. He is the chair of the IAG Sub-Commission 4.4 "GNSS Integrity and Quality Control." 